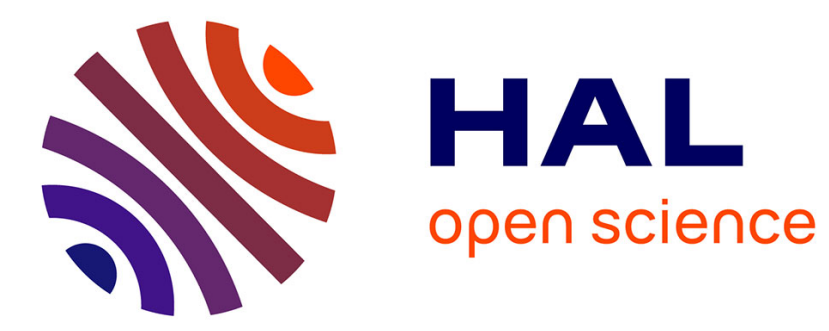

\title{
Perceiving rhythm where none exists: Event-Related Potential (ERP) correlates of subjective accenting
}

\author{
D. Potter, M. Fenwick, D. Abecasis, Renaud Brochard
}

\section{To cite this version:}

D. Potter, M. Fenwick, D. Abecasis, Renaud Brochard. Perceiving rhythm where none exists: Event-Related Potential (ERP) correlates of subjective accenting. Cortex, 2009, 1 (45), pp.103-109. 10.1016/j.cortex.2008.01.004 . hal-00570452

HAL Id: hal-00570452

https://u-bourgogne.hal.science/hal-00570452

Submitted on 5 May 2011

HAL is a multi-disciplinary open access archive for the deposit and dissemination of scientific research documents, whether they are published or not. The documents may come from teaching and research institutions in France or abroad, or from public or private research centers.
L'archive ouverte pluridisciplinaire HAL, est destinée au dépôt et à la diffusion de documents scientifiques de niveau recherche, publiés ou non, émanant des établissements d'enseignement et de recherche français ou étrangers, des laboratoires publics ou privés. 


\title{
Perceiving rhythm where none exists: Event-related potential (ERP) correlates of subjective accenting
}

\author{
Douglas D. Potter, Maggi Fenwick, Donna Abecasisand Renaud Brochard
}

\section{Abstract}

Previous research suggests that our past experience of rhythmic structure in music results in a tendency for Western listeners to subjectively accent equitonal isochronous sequences. We have shown in an earlier study that the occurrence of a slightly softer tone in the 8th to 11th position of such a sequence evokes a P300 event-related potential (ERP) response of different amplitudes depending on whether the tone occurs in putatively subjectively accented or unaccented sequence positions (Brochard et al., 2003). One current theory of rhythm processing postulates that subjective accenting is the result of predictive modulations of perceptual processes by the attention system. If this is the case then ERP modulations should be observed at an earlier latency than the P300 and these should be observed in ERPs to both standard and softer tones. Such effects were not observed in our previous study. This was possibly due to the use of a linked-mastoid reference which may have obscured lateralized differences. The aim of the present study was to replicate the previous auditory P300 subjective accenting findings and to investigate the possibility that these effects are preceded by ERP changes that are indicative of rhythmic modulation of perceptual processing. Previous auditory P300 findings were replicated. In addition and consistent with current theories of rhythm processing, early brain ERP differences were observed both in standard and deviant tones from the onset of the stimulus. These left lateralized differences are consistent with a rhythmic, endogenously driven, modulation of perception that influences the conscious experience of equitonal isochronous sequences.

Keywords: Music; Rhythm; Perception; Asymmetry; Attention 


\section{Introduction}

While rhythm surrounds us throughout our whole life and isinherent in many mental activities, the neural mechanismsunderlying rhythm perception remain largely unclear. Theperception of rhythm is a dynamic process which involves thesynchronisation of external musical stimuli with internalrhythmic processes (Jones and Boltz, 1989). Rhythm oftenrefers to the organization of events in time, such that they areorganized perceptually into groups. For instance, theperception of meter, i.e. the tendency to periodically group sound events, perceiving an alternation of accented ("strong")and unaccented ("weak") beats, takes place even in perfectlyregular sequences of identical tones. This type of subjectiveaccent imposed by listeners has long been described inbehavioural studies (Bolton, 1894; Woodrow, 1909; Fraisse,1982; Drake, 1993; Parncutt, 1994) where spontaneousgrouping and accenting of tones, most frequently by twos orfours, have been reported. While the underlying cause ofthese simple forms of subjective accenting is not clear, it isevident that cultural differences in experience of musicalrhythms influence the accuracy of perception of morecomplex rhythms (Hannon and Trehub, 2005). Thesephenomena are consistent with most theoretical conceptionsof meter as a hierarchical structure.In the present study we are interested in determiningwhether there is evidence of the most basic level of metricalstructure, which corresponds to an alternation of strong andweak beats. An important assumption is that the first stimulusin the sequence is more salient and receives moreattention than following items (Thomassen, 1982) and, asa consequence, establishes the pattern of accenting within anisochronous sequence. Such accenting effects are consistentwith a generative model of representation structure in thebrain (Friston, 2002). In this model, the brain is continuallypredicting current spatio-temporal patterns of input on thebasis of past patterns of input and new stimuli are accommodatedwithin pre-existing representational structures.

Thus the perception of stimuli may be subtly altered by priorexpectations. If, however, a stimulus deviates significantlyfrom these expectations, error signals will be generated toallow accommodation of this new information within preexistingstructures. These signals can be detected using eventrelatedpotential (ERP) measures. For example, such errorsignals 
may be detected as a mismatch negativity (MMN) or, ifthe signal deviates considerably, this may result in the activationof attention mechanisms marked by an N2/P3 ERPcomplex. In previous research (Brochard et al., 2003) it wasfound that a $4 \mathrm{~dB}$ reduction in tone amplitude, introduced inthe latter part of an isochronous equitonal sequence, is processeddifferently depending on whether it occurs in odd(putatively subjectively accented) rather than even (putativelysubjectively unaccented) positions. Softer tones in oddnumberedpositions evoked a larger P300 brain ERP response, reflecting an apparent binary pattern of metrical accentuation(Abecasis et al., 2005). This component, peaking at about 300-600 msec post-stimulus onset, is elicited by violations oflisteners' expectancies and both its amplitude and latencydepend upon listeners' attention and the degree of difficulty inthe decision-making process of the task, in this case countingthe number of infrequent lower amplitude tones (Donchinand Coles, 1988; Janata, 1995; Besson and Faïta, 1995; Polichand Kok, 1995; Granot and Donchin, 2002). The differences inP300 amplitude provide clear evidence of a subjective differencein the processing of softer (deviant) tones in odd andeven sequence positions but did not provide any basis fordetermining how early this subjective accenting effect influencesstimulus processing. Jones (Jones, 1976; Jones and Boltz,1989; Drake et al., 2000) postulates that attention is synchronizedto regular auditory sequences, through rhythmicalexpectancies for the occurrence of the next salient beat. Onthis basis one would predict that ERP modulations mightdistinguish subjectively accented and unaccented tones, possibly from stimulus onset or before stimulus onset. Thiswas not, however, observed in our previous study (Brochardet al., 2003). The lack of earlier differences between the ERP responsesto putatively accented and unaccented tone stimuli couldhave been due to the use of a linked-mastoid reference.

Although often chosen as neutral reference for ERP recordings, these sites are sensitive to activity in primary stages ofauditory processing in the cortex. If activation at the twolinked-mastoid electrode sites is different then a current willflow between the electrodes and cause local distortion of therecording of field potentials from the surface of the head. Thismay have resulted in the masking of low level accentingeffects emanating from the temporal region and post-hoc rereferencingwould not resolve this problem. In this studya midline reference was used to remove this confound.It is also likely 
that dynamic modulations of perceptualprocesses should be lateralized to the left hemisphere (Platelet al., 1997; Potter et al., 2000; Vuust et al., 2005). In the positronemission tomography study of Platel et al. participantsselectively attended to familiarity, pitch, rhythm and timbreof randomly arranged sequences of notes. Attending tofamiliarity, pitch and rhythm preferentially activated lefthemisphere sites and attending to timbre activated frontalregions of the right hemisphere. In the Potter et al. ERP studyparticipants were instructed simply to listen to modernpolyrhythmic African music for a brief period of time. A singletrial across-subject averaging technique was used to visualizecommon ERP deflections. ERP deflections that were synchronizedto the music and located predominantly over the lefthemisphere were observed. In this latter study regions of thebrain associated with auditory processing appear to be drivenby complex structure of the rhythmical sequences in themusic. Vuust et al. (2005) used the MMN as a measure ofsensitivity to rhythmic structure. They found that bothmusicians and non-musicians produce an $\mathrm{MMN}$ to temporalviolations of rhythmic structure. However, musiciansproduced a larger response over the left than right hemispheresuggesting an effect of training on lateralization ofrhythm processing. The MMN also had a shorter latency inmusicians than nonmusicians. In the present study theassumption is that our extensive experience with music willresult in individuals imposing a simple implicit rhythmicstructure on the isochronous equitonal stimuli that they listento and that this will be more strongly lateralized to the lefthemisphere in trained musicians. In the present study a nosereference was used and mastoid electrodes adjacent to thetemporal lobe were included as active electroencephalogram(EEG) recording sites to maximize the likelihood of detectingevidence of subjective accenting effects occurring in corticalregions involved in auditory perception.

Previous research would suggest that dynamic modulationsof attention predicted by Jones and collaborators (Jones,1976; Jones and Boltz, 1989; Drake et al., 2000) might take theform of a "processing negativity" (PN) in the eventrelatedbrain potentials generated by the presentation of tonesequences (Naïätänen, 1982, 1992). These ERP modulationswere first described in dichotic listening tasks as the negative shift found in attended as compared to unattended channels(Hillyard et al., 1973; Näataänen et al., 1978) and these differencesmay start as early as $50 \mathrm{msec}$ post-stimulus onset. Apotentially 
confounding effect resulting from the short interstimulusinterval (ISI) used in this and previous studies is thatany early effects that were observed could result from overlappingERP deflections from the previous stimulus. Forinstance, Starr et al. (1997) found a negative slow wave in ERPsto frequent standard tones around 380-680 msec post-stimulusonset that increased in amplitude throughout a stimulussequence, being larger before, than after, a deviant toneoccurred. However, in the present study we predict a dynamic'subjective accenting' modulation that will affect tones basedon their position in the sequence and not their actual amplitude.In addition the accented beat naturally precedes theunaccented beat in the simplest rhythm structures suggestingthat an opposite pattern of relative negativity would beobserved in the present study. In summary, previous research suggests that individualssubconsciously impose rhythmic structure to isochronousequitonal sequences and this can be demonstrated as modulationsof the P300 ERP using a target detection paradigm(Brochard et al., 2003). The main aim of the present study wasto test the hypothesis that the P300 effects, associated withthe end of stimulus evaluation, are preceded by differences inERP deflections that mark dynamic modulations of perceptualprocesses by attention mechanisms (Jones, 1976; Jones andBoltz, 1989; Drake et al., 2000) or the activation of temporallybound rhythmic representation structures as suggested bygenerative models of perception (Friston, 2002). These ERPdeflections should occur from stimulus onset as they representan imposition of structure on the input rather than thedetection of deviation from expected input. As such themodulation should be present in response to both infrequentdeviant and frequent standard tones that occur in putativelysubjectively accented positions in the latter part of tonesequences. The same oddball paradigm as employed byBrochard et al. (2003) was used. Only musically trainedparticipants were recruited for this experiment since, in ourprevious study, musicians produced more robust effects ofsubjective accenting on the P300.

\section{Methods}

Ten volunteer participants (seven male, three female) withnormal hearing took part in this study. The age range was 22-55 years old (mean age $1 / 4$ $43.3 \mathrm{yrs}$ ). All participants hada minimum of 8 years formal music training 
(mean1/4 9.4 yrs).Each participant gave their written consent after the nature ofthe experiment was fully explained to them.Stimuli consisting of isochronous sequences of 13-16 70dBSPL standard tones were created (to avoid inducing a $4 / 4$ meter). One or two of the tones in each sequence werereplaced by $66 \mathrm{~dB}$ SPL deviant tones. The first deviant tonecould occur in one of four different positions in eachsequence. These positions corresponded to either a subjectivelyaccented beat (positions 9 or 11) or a subjectivelyunaccented beat (positions 8 or 10). A $4 \mathrm{~dB}$ decrease in volumeis considered a slight change for an individual to detect and isequivalent to the size of a subjective accent (Povel andOkkerman, 1981; see Brochard et al., 2003). Each tone hada frequency of $440 \mathrm{~Hz}$ and duration of $50 \mathrm{msec}$ and rise and falltime of $10 \mathrm{msec}$. Half of the sequences contained one $66 \mathrm{dBdeviant}$ tone, and half contained two $66 \mathrm{~dB}$ deviant tones toreduce predictability and maintain attentiveness. Wherethere were two $66 \mathrm{~dB}$ deviant tones, only the first of these wereused in the analysis. The ISI in a sequence was $600 \mathrm{msec}$.During the EEG recordings, the stimuli were presentedbinaurally via headphones. Participants were instructed tovisually fixate on a small red circle placed at a distance of 2 mand to minimize both body and eye movements. Participantswere then instructed to count the number of infrequent,deviant, soft tones they heard in each sequence and reportthis at the end of the sequence. When participants reported nosoft tones; one soft tone when there were actually two; twosoft tones when there was actually one; or more than two softtones, these were counted as error trials. It should be notedthat these deviant soft tones are effectively target stimuli forthe participant and are sometimes labeled as such in P300experiments that involve active detection of infrequentdeviant stimuli. No feedback on accuracy was provided duringthe task. In order to minimize guessing and predictability, within each block of trials the sequences were presentedrandomly. A block of trials consisted of 16 isochronoussequences and each participant was presented with six blocksof trials. The blocks were separated by short rest periods of $30 \mathrm{sec}$. The test duration was approximately 25 min. Participantswere briefly interviewed post-testing to obtain feedbackregarding the degree of difficulty of the task. Each participantcommented that the occurrence and frequency of the softertones were unpredictable which suggests that no simpleresponse bias was operating.Continuous EEG was recorded using Contact Precisionamplifiers and 
Neuroscan software with silver/silver chlorideelectrodes mounted in an Easycapheadcap. The EEG wasrecorded $(.03-100 \mathrm{~Hz}$ band pass; $400 \mathrm{~Hz}$ digitization rate; offlinelow-pass filter: $45 \mathrm{~Hz}, 48 \mathrm{~dB} /$ oct) with 11 electrodesattached to the scalp along the midline $(\mathrm{Fz}, \mathrm{Cz}, \mathrm{Pz})$, temporalregion (LT, between T7 and FT7, RT, between T8 and FT8), parietal region (P3, P4) and the left and right mastoids (LM,RM). The electro-oculogram (EOG) was monitored from electrodesplaced on the infraorbital and supraorbital ridges of theright eye (vertical eye movements, VEOG) and at the outercanthus of both eyes (horizontal eye movements, HEOG). Thereference electrode was placed on the nose. Impedances forall participants were 4-7 kohms. EEG epochs (_100 to900 msec with respect to the stimulus onset) were averagedseparately for $66 \mathrm{~dB}$ and $70 \mathrm{~dB}$ stimuli for both the putativelysubjectively accented and unaccented stimuli. The pre-stimulusinterval was used for baseline correction. All samplescontaining EEG artifacts greater than b/_60 mV were rejected Repeated measures analysis of variance (ANOVA) wascarried out on mean amplitude measurements from selectedtime windows of the ERPs. The factors used in the analysiswere tone amplitude (standard/deviant), subjective accenting(subjectively accented/subjectively unaccented) and electrodesite. Separate analyses were carried out on midline and lateralelectrodes depending on the specific feature of the ERPdeflection that was being analyzed. The Greenhouse-Geissercorrection was applied in cases where there were more thantwo levels in a factor. Original degrees of freedom and correctedsignificance levels are given.

\section{Results}

Participants made an average of $15 \%$ errors in identifying thecorrect number of $66 \mathrm{~dB}$ tones in the sequences. The grandaveraged waveforms for the subjectively accented and unaccentedstandard and deviant tones are illustrated in Fig. 1.Deviant tones evoke an N2/P300 complex and the P300 islarger when the deviant tone occurs in a putatively subjectivelyaccented position in the tone sequence.Mean amplitude measures at the midline sites $\mathrm{Fz}, \mathrm{Cz}$ andPz in the latency range $500-600 \mathrm{msec}$ are illustrated in Fig. 2.ANOVA of these data, with factors of tone amplitude,subjective accenting and electrode site $(\mathrm{Fz}, \mathrm{Pz}, \mathrm{Cz})$ producedthe following. As predicted, deviant tones evoked significantlylarger ERPs than standards $(F(1,9) \quad 1 / 411.65$, p $1 / 4.008$, ES $1 / 4$ 
.564).There was also a significant interaction between tone amplitudeand subjective accenting $(F(1,9) 1 / 47.36, p 1 / 4.02, E S 1 / 4.450)$ due to $P 300$ responses to deviants being larger in the subjectivelyaccented positions than the unaccented ones. Therewas no three-way interaction between accenting, toneamplitude and site.It is evident in Fig. 1 that accented standard tones arerelatively more negative than unaccented standard tones inthe latency range $200-500 \mathrm{msec}$. Mean amplitude measures inthis latency range were used to characterise this difference.ANOVA with factors of accenting, hemisphere, and site(temporal, mastoid, parietal) revealed the following. ERPs toputatively subjectively accented tones were significantly morenegative than those to putatively unaccented tones $(F(1,9) \quad 1 / 46.11, \quad p \quad 1 / 4.035$, ES $\quad 1 / 4$.404). A significant interactionbetween accenting and hemisphere was also observed(F(1,9) $1 / 46.01$, $\mathrm{p} 1 / 4.037, \mathrm{ES} 1 / 4.400$ ) and this was due to a largeraccenting effect over the left hemisphere than the righthemisphere. There was no significant interaction between site(anterior-posterior) and hemisphere or accent.Both the attention synchronisation theory of Jones andBoltz (1989) and predictive coding theory suggest that earlysubjective accenting effects may be observable in ERPs at sites close to auditory cortex.
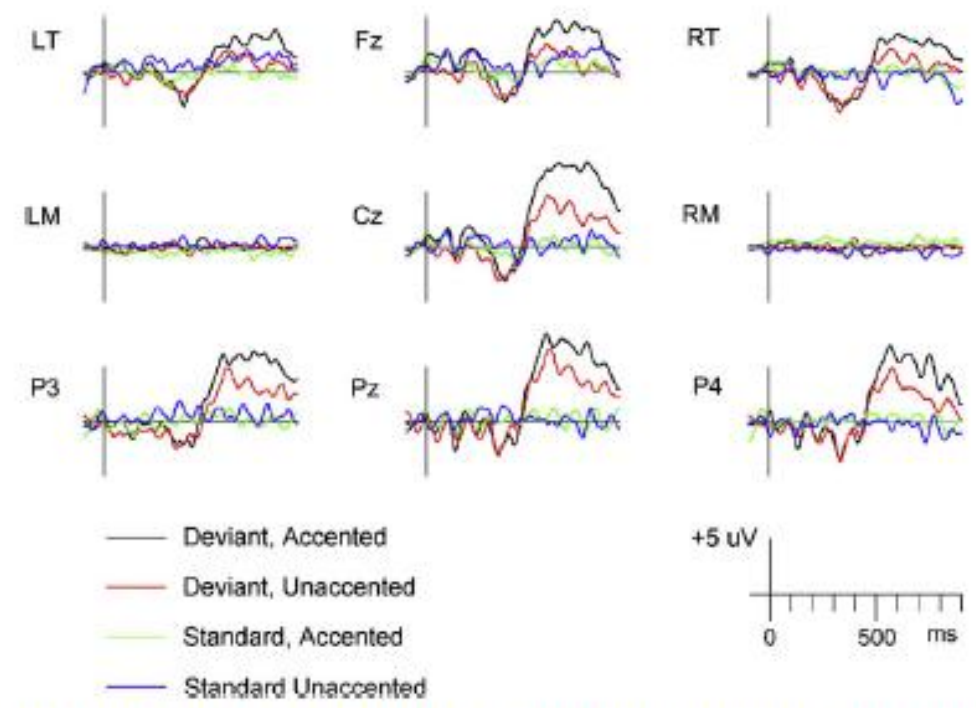

Fig. 3 - Grand averaged ERPs evoked by frequent standard 70dB and infrequent deviant $66 \mathrm{~dB}$ tones in putative subjectively accented and unaccented sequence positions, re-referenced to linked-mastoids. Although the effect of subjective accenting on P300 is preserved, the early onset accenting effect over the left hemisphere is no bnger present. 


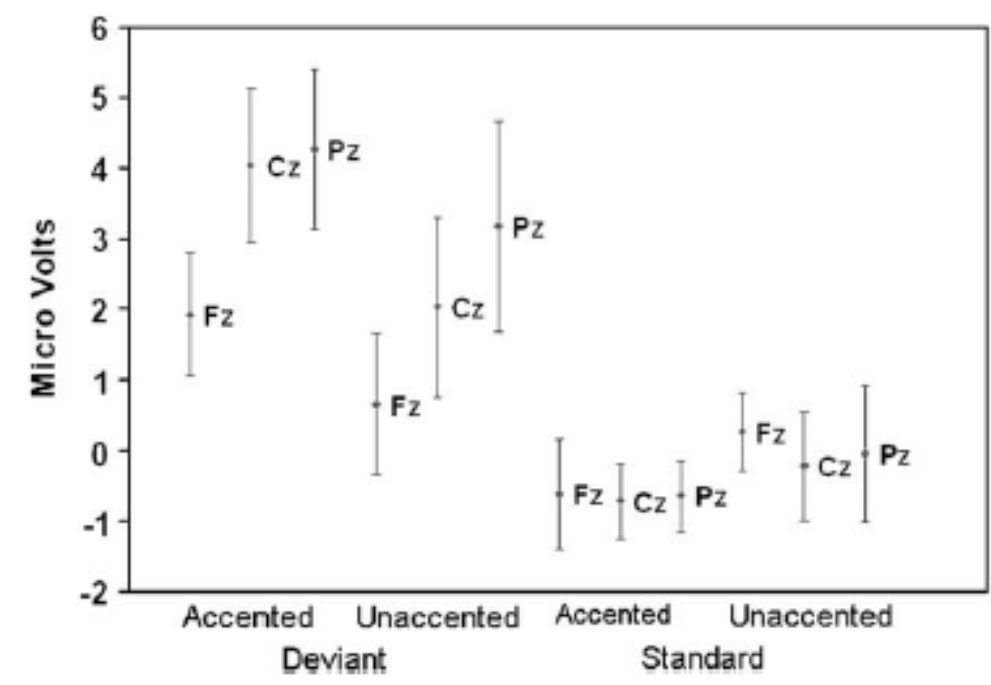

Fig. 2 - Distribution of mean amplitude of P300 at midline electrode sites in the latency range $500-600 \mathrm{msec}$ evoked by putative subjectively accented and unaccented deviant and standard tones. Error bars indicate $+/-1$ standard error of mean.

LT

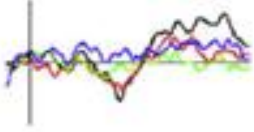

LM

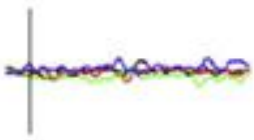

P3

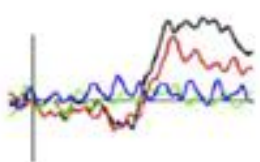

$\mathrm{Fz}$
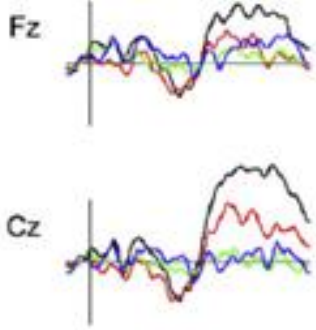

$\mathrm{Pz}$

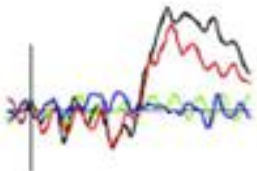

RT

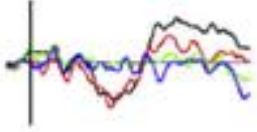

RM

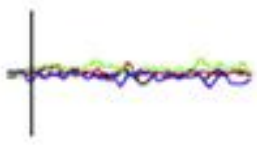

P4

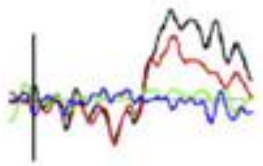

$+5 \mathrm{uV}$

Deviant, Unaccented

Standard, Accented

Standard Unaccented

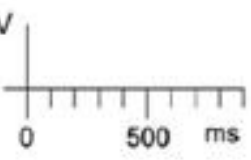

Grand averaged ERPs evoked by frequent standard $70 \mathrm{~dB}$ and infrequent deviant $66 \mathrm{~dB}$ tones in putative subjectively d and unaccented sequence positions, re-referenced to linked-mastoids. Although the effect of subjective accenting $I$ is preserved. the early onset accenting effect over the left hemisohere is no longer present.

It can be seen in Fig. 1 that the ERPdeflections are more negative in the subjectively accentedconditions at the mastoid electrodes in the first $100 \mathrm{msec}$ afterstimulus onset. ANOVA of mean amplitudes of the ERPs at themastoid sites in the latency range 0-100 msec with 
factors ofsubjective accenting, tone amplitude and hemisphere wascarried out. Mean amplitudes in this latency range weresignificantly more negative in the accented conditions thanthe unaccented conditions $(F(1,9) \quad 1 / 49.95, p \quad 1 / 4.012$, ES $1 / 4.525)$. The predicted interaction between subjective accenting andhemisphere was not significant $(F(1,9) 1 / 42.07, p 1 / 4.184$, ES $1 / 4.187)$. However, separate exploratory analyses of thesubjective accenting effects at left and right mastoid electrodesindicated that the effect was significant at the leftelectrode $(F(1,9) 1 / 47.31, p 1 / 4.024$, ES $1 / 4.448)$ but not the rightelectrode $(F(1,9) 1 / 43.34, p 1 / 4.101$, ES $1 / 4.271)$. Averages were digitally re-referenced to a linked-mastoid toallow comparison with the previous study of Brochard et al.(2003) and are illustrated in Fig. 3. ANOVA of mean amplitudemeasures in the latency range 500900 msec at $\mathrm{Cz}$, with factorsof subjective accent and tone amplitude revealed that the P300evoked by $66 \mathrm{~dB}$ deviant tones was significantly different fromERPs to standard $70 \mathrm{~dB}$ tones $(F(1,9) \quad 1 / 4$ 11.53, p $1 / 4.008, E S 1 / 4.562$ ). There was no main effect of subjective accent but there wasa significant interaction between subjective accent and toneamplitude $\left(F(1,9) 1 / 45.77, \mathrm{p}^{1 / 4} .040, E S 1 / 4.391\right)$. This was due toa significant difference in the amplitude of the P300 evoked byputatively subjectively accented and unaccented $66 \mathrm{~dB}$ tones $(F(1,9)$ $1 / 4$ 6.13, p1/4.035, ES1/4.405). It can be seen in Fig. 3 thatusing this reference masks the early accenting effect that ispresent in the 0$100 \mathrm{msec}$ latency range, though subsequentlysuch an effect can be seen in the latency range $200-400 \mathrm{msec}$ attemporal and parietal sites. These latter differences are not,however, significant.

\section{Discussion}

The main aim of this study was to test the hypothesis thatextensive exposure to rhythmic structures in music will lead toa tendency to perceive isochronous equitonal sequences ashaving, by default, a 
binary accented structure that is probablysynchronized to the first beat in the sequence. Such anobservation would be consistent with the finding that we are,in general (and musicians in particular), very sensitive todiscrepancies of timing in music and that these effects can bedetected in brain responses associated with preattentiveprocessing (Vuust et al., 2005). Our previous research (Brochardet al., 2003) provided indirect evidence of accenting effects inthe form of modulations of P300 amplitude but not earlier ERPmodulations. The present finding of an ERP modulation in thelatency range $0-100 \mathrm{msec}$ that may be associated withsubjective accenting is consistent with the dynamic attendingtheory of rhythm processing (Jones, 1976; Jones and Boltz,1989; Drake et al., 2000). However, it is also possible thatdynamic modulations of perceptual processing occur, asa result of predictive processes that are an inherent part of preattentiveprocessing (Friston, 2002). The present study does notdistinguish between these two theoretical accounts of thebasis of subjective accenting effects.Putative subjectively accented standard tones were relativelymore negative than subjectively unaccented standardtones in the 200-500 msec latency range. In contrast the ERP responses to deviant tones no longer differed at the latency ofthe N2. The active detection of the deviant tones may lead tothe reorienting of attention (Astafiev et al., 2006) and the resetting of subjective accenting. However, this remains to bedetermined.A concern regarding the early negative deflections thatwereobserved in this study is the possibility that they were a nonspecificeffect associated with anticipation of infrequentdeviant stimuli. Negative shifts have been hypothesized toreflect anticipatory activity (Kotchoubey, 2006) that may welloverlap the early part of the ERP to the following stimulus (Starret al., 1995; Kotchoubey, 2006). For example, a late slow waveobserved by Starr et al. (1997) in ERPs to standard tones showednegative polarity and a frontal distribution 
before the occurrenceof an infrequent deviant tone, and was assumed to berelated to listeners' attention to and expectation of the devianttone. This explanation seems unlikely in the present study asthe early negativity observed at the mastoid site was observedto both deviant and standard tones. The sustained leftlateralisednegative ERP deflection, evoked only by accented standardtones, does not fitwithKotchoubey's anticipationmodel either.It seems possible that the negative deflections observed inthe present study might be properly classified as "processingnegativities" that reflect the extent of attention allocation(Alho et al., 1987; Higashima et al., 2004). Whether these processingnegativities are generated by the same mechanismthat generates the $\mathrm{Nd}$ remains to be determined. The Ndconsists of an early and a late component, originating inauditory and frontal areas, respectively (Giard et al., 2000). It ispossible that the subjective accenting effect observed at themastoid site is an example of the early $\mathrm{Nd}$ deflection thatoriginates in the auditory cortex. However, the onset of theeffect was earlier than is typically described in the case of theNd. Finally, lateralization of the observed accenting effects tothe left hemisphere is consistent with previous observationsthat attention to rhythm tends to activate regions of the lefthemisphere more than the right hemisphere (Platel et al.,1997; Potter et al., 2000; Vuust et al. 2005).

The results of this study strongly support our previousfindings (Brochard et al., 2003; Abecasis, et al. 2005) byprovidingreplicable physiological evidence of subjective accenting. Earlydifferences between "accented" and "unaccented" positions inthe tone sequence, whatever the intensity of the tone, couldreflect early segmentation of the tone sequence into groups oftwo events (Fraisse, 1982; Handel, 1989).As stated earlier, the findings are also consistent with anattention based account of rhythm perception, 
such as Jones'dynamic attending theory (Jones and Boltz, 1989; see Kotchoubey,2006). Attention can alter neural activity in the auditorysystem at the level of the cochlea (e.g. Maison et al., 2001),brainstem and thalamic nuclei (e.g. Hirschhorn and Michie,1990), as well as early positive and negative obligatory corticalcomponents (see Woldorff et al., 1993) and the level at whichthe modulations observed in this study first occur remains tobe determined. However, the present findings do not rule outthe possibility that these effects result from the predictivenature of temporal representation structures (Friston, 2002)and this would not necessarily involve dynamic modulationsof perceptual systems by attention.The findings of this study provide further evidence that ourperceptions of rhythmic structure in auditory events aresignificantly influenced by our prior experience. Further linesof research might include a more detailed study of the stage atwhich auditory processing is affected by attention, a moredetailed consideration of the effect of either implicit orexplicit musical expertise, or indeed the effects of recentrhythmic pattern experience on the perception of subsequentisochronous stimulus sequences.

\section{references}

Abecasis D, Brochard R, Granot R, and Drake C. Differential brainresponse to metrical accents in isochronous auditorysequences. Music Perception, 22: 549-562, 2005.

Alho K, TöttöläK, Reinikainen K, Sam $M$, and Näätänen R. Brainmechanism of selective listening reflected by eventrelatedpotentials. Electroencephalography and Clinical Neurophysiology,68: 458-470, 1987.

Astafiev SV, Shulman GL, and Corbetta M. Visuospatialreorienting signals in the human temporo-parietal junctionare independent of 
response selection. European Journal ofNeuroscience, 23: 591-596, 2006.

Besson $M$ and Faïta F. An event-related potential (ERP) study ofmusical expectancy: comparison of musicians with nonmusicians.Journal of Experimental Psychology: Human Perceptionand Performance, 21: 1278-1296, 1995.

Bolton TL.Rhythm. American Journal of Psychology, 6: 145-238, 1894.

Brochard R, Abecasis D, Potter D, Ragot R, and Drake C. The ticktockof our internal clock: evidence of subjective accents inisochronous sequences. Psychological Science, 14: 362-366, 2003.

Donchin E and Coles MGH. Is the P300 componenta manifestation of context updating? Behavioral and BrainSciences, 11: 357-374, 1988.

Drake C, Jones MR, and Baruch C. The development of rhythmicattending in auditory sequences: attunement, referent period,focal attending. Cognition, 77: 251-288, 2000.

Drake C. Reproduction of musical rhythms by children, adultmusicians, and adult non-musicians. Perception andPsychophysics, 53: 25-33, 1993.

Fraisse P. Rhythm and tempo. In Deutsch D (Ed), The psychology ofmusic. New York: Academic Press, 1982.

Friston K. Beyond phrenology: what can neuroimaging tell usabout distributed circuitry? Annual Review of Neuroscience, 25:221-250, 2002.

Giard $\mathrm{M}-\mathrm{H}$, Fort A, Mouchetant-Rostaing $\mathrm{Y}$, and Pernier J. Neurophysiological mechanisms of auditory selectiveattention in humans. Frontiers in Bioscience, 5: 84-94, 2000. 
Granot R and Donchin E. Do Re MiFa Sol La Ti - constraints,congruity, and musical training: an event-related brainpotentials study of musical expectancies. Music Perception, 19:487-528, 2002.

Handel S. Listening: an introduction to the perception of auditoryevents. Cambridge, MA: MIT Press, 1989.

Hannon EE and Trehub SE. Metrical categories in infancy andadulthood.Psychological Science, 16: 48-55, 2005.

Higashima M, Nagasawa T, Kawasaki Y, Oka T, Sakai N,Tsukada T, et al. Event-related potentials elicited by nontarget tones in an auditory oddball paradigm in schizophrenia.International Journal of Psychophysiology, 51: 189-200, 2004.

Hillyard SA, Hink RF, Schwent VL, and Picton TW. Electrical signs ofselective attention in the human brain. Science, 182: 177-180, 1973. Hirschhorn TN and Michie PT. Brainstem auditory evoked potentials (BAEPS) and selective attention revisited. Psychophysiology, 27: 495-512, 1990.

Janata P. ERP measures assay the degree of expectancy violationof harmonic contexts in music. Journal of Cognitive Neuroscience,7: 153-164, 1995

Jones MR. Time, our lost dimension: toward a new theory ofperception, attention, and memory. Psychological Review, 83:323355, 1976.

Jones $\mathrm{MR}$ and Boltz $\mathrm{M}$. Dynamic attending and responses to time.Psychological Review, 96: 459-491, 1989.

Kotchoubey B. Event-related potentials, cognition, and behavior:a biological approach. Neuroscience and Biobehavioral Reviews,30: 4265, 2006. 
Maison S, Micheyl C, and Collet L. Influence of focused auditoryattention on cochlear activity in humans. Psychophysiology, 38:35-40, 2001.

Näätänen R. Attention and brain function. Hillsdale, NJ: LawrenceErlbaum, 1992.

Näätänen R, Awk Gaillard, and Mantysalo S. Early selectiveattentioneffect on evoked potential reinterpreted. ActaPsychologica, 42: 313-329, 1978.

Näätänen R. Processing negativity: an evoked-potential reflectionof selective attention. Psychological Bulletin, 92: 605-640, 1982.

Parncutt R. A perceptual model of pulse salience and metricalaccent in musical rhythms. Music Perception, 11: 409-464, 1994.

Platel H, Price C, Baron JC, Wise R, Lambert J, Frackowiak RSJ, et al.The structural components of musical perception -a functional anatomical study. Brain, 120: 229-243, 1997.

Polich J and Kok A. Cognitive and biological determinants of P300:an integrative review. Biological Psychology, 41: 103-146, 1995.

Potter DD, Sharpe H, Basbinar D, and Jory S. Insights into thefunctional organization of music processing revealed usingcontinuous across-subject event-related potential averaging.In Woods C, Luck GB, Brochard R, O'neill SA, and Sloboda JA(Eds), Proceedings of the sixth international conference on musicperception and cognition. Keele, Staffordshire, UK: Departmentof Psychology, 2000.

Povel DJ and Okkerman H. Accents in equitone sequences.Perception and Psychophysics, 30: 565-572, 1981. 
Starr A, Aguinaldo T, Roe M, and Michalewski HJ. Sequentialchanges of auditory processing during target detection: motorresponding versus mental counting. Electroencephalography andClinical Neurophysiology, 105: 201-212, 1997.

Starr A, Sandroni P, and Michalewski HJ. Readiness to respond ina target detection task: pre- and post-stimulus event-relatedpotentials in normal subjects. Electroencephalography andClinical Neurophysiology, 96: 76-92, 1995.

Thomassen MT. Melodic accent: experiments and a tentativemodel. Journal of the Acoustical Society of America, 71: 1596-1605,1982.

Vuust P, Pallesen KJ, Bailey C, Van Zuijen TL, Gjedde A,Roepstorff A, et al. To musicians, the message is in the meter:pre-attentive neuronal responses to incongruent rhythm areleft-lateralized in musicians. Neurolmage, 24: 560-564, 2005.

Woldorff MG, Gallen CC, Hampson SA, Hillyard SA, Pantev C,Sobel D, et al. Modulation of early sensory processing inhuman auditory cortex during auditory selective attention.Proceedings of the National Academy of Sciences of the United Statesof America, 90: 8722-8726, 1993.

Woodrow H. A quantitative study of rhythm. Archives ofPsychology, 14: 1-66, 1909. 